\title{
Loss of nonsense mediated decay suppresses mutations in Saccharomyces cerevisiae TRA1
}

\author{
Stephanie Kvas, Gregory B Gloor and Christopher J Brandl ${ }^{*}$
}

\begin{abstract}
Background: Tra1 is an essential protein in Saccharomyces cerevisiae. It was first identified in the SAGA and NuA4 complexes, both with functions in multiple aspects of gene regulation and DNA repair, and recently found in the ASTRA complex. Tra1 belongs to the PIKK family of proteins with a C-terminal PI3K domain followed by a FATC domain. Previously we found that mutation of leucine to alanine at position 3733 in the FATC domain of Tra1 (tra1-L3733A) results in transcriptional changes and slow growth under conditions of stress. To further define the regulatory interactions of Tra1 we isolated extragenic suppressors of the tra1-L3733A allele.

Results: We screened for suppressors of the ethanol sensitivity caused by tra1-L3733A. Eleven extragenic recessive mutations, belonging to three complementation groups, were identified that partially suppressed a subset of the phenotypes caused by tra1-L3733A. Using whole genome sequencing we identified one of the mutations as an opal mutation at tryptophan 165 of UPF1/NAM7. Partial suppression of the transcriptional defect resulting from tra1-L3733A was observed at GAL10, but not at PHO5. Suppression was due to loss of nonsense mediated decay (NMD) since deletion of any one of the three NMD surveillance components (upf1/nam7, upf2/nmd2, or upf3) mediated the effect. Deletion of upf1 suppressed a second FATC domain mutation, tra1-F3744A, as well as a mutation to the PIK3 domain. In contrast, deletions of SAGA or NuA4 components were not suppressed.

Conclusions: We have demonstrated a genetic interaction between TRA1 and genes of the NMD pathway. The suppression is specific for mutations in TRA1. Since NMD and Tra1 generally act reciprocally to control gene expression, and the FATC domain mutations do not directly affect NMD, we suggest that suppression occurs as the result of overlap and/or crosstalk in these two broad regulatory networks.
\end{abstract}

Keywords: Tra1, Yeast, Nonsense mediated decay, Upf1, Gene expression, Second-site suppression

\section{Background}

Tra1 is a 3744 amino acid residue protein, essential for viability in Saccharomyces cerevisiae. It is a major constituent of the SAGA and NuA4 transcriptional regulatory complexes [1-3], both with significant roles in gene regulation and DNA repair [4-6]. More recently a putative complex based on mutual associations termed ASTRA, was also found to contain Tra1 [7]. Tra1's mammalian homo$\log$ TRRAP was identified because of its interactions with the transcription factors c-myc and E2F [8]. Similarly Tra1 interacts with yeast transcriptional activators to target SAGA and NuA4 to promoters [9-12]. Interestingly, Helmlinger et al. [13] have recently provided evidence that

\footnotetext{
* Correspondence: cbrandl@uwo.ca

Department of Biochemistry, Schulich School of Medicine \& Dentistry, The University of Western Ontario, London N6A5C1, Canada
}

Tra1 also acts independently of SAGA and NuA4 to regulate gene expression.

Tra1/TRRAP are members of the PIKK (phosphoinositide three-kinase-related kinase) family of proteins, a group that in yeast includes Tor1, Tor2, Tel1 and Mec1 $[14,15]$. The latter two are structurally and functionally related to ATM and ATR of multicellular eucaryotes. Two additional family members not found in yeast, are the DNA-PKcs (DNA-dependent protein kinase catalytic subunit) and SMG-1, with key roles in DNA repair and nonsense mediated decay of RNA, respectively. The PIKK family members are all large proteins characterized by a common arrangement of C-terminal domains [16], including a domain that resembles the phosphatidylinositol-3-kinases (PI3K). Unlike the other PIKK molecules, which are protein kinases, Tra1/TRRAP lacks kinase activity $[2,8]$. Nonetheless, altering residues that parallel
C Biomed Central

(C) 2012 Kvas et al; licensee BioMed Central Ltd. This is an Open Access article distributed under the terms of the Creative Commons Attribution License (http://creativecommons.org/licenses/by/2.0), which permits unrestricted use, distribution, and reproduction in any medium, provided the original work is properly cited. 
key regions of the kinase members of the family affect Tra1 function [17]. On the N-terminal side of the kinase domain is the HEAT and TPR repeat-rich FAT (FRAPATM-TRRAP) domain [18-21]. C-terminal to the PI3K domain is the less highly conserved PRD (PIKK regulatory domain), identified in ATM as the site of acetylation by TIP60 [22].

The $~ 35$-residue FATC domain is at the extreme Cterminus of the PIKK proteins [18]. The critical role of the FATC domain is evident from the finding that addition of a single glycine to the C-terminus of Tra1 abolishes function, and mutations of L3733 or F3744 to alanine result in slow growth in a number of stress conditions [23]. The FATC domain is similarly important for the other PIKK family members; for example, the parallel mutation to L3733A of Tra1 results in a dramatic loss in the kinase activity of SMG-1 [24]. Dames et al. [25] determined the structure of the isolated FATC domain of S. cerevisiae Tor1. It is predominately helical with a loop at the extreme $\mathrm{C}$-terminus held in place by a disulphide linkage. The helical structure is likely conserved in the family, but not the loop because the two cysteines are only found in the Tor proteins. FATC domains are proposed to be a target for interacting proteins. In a twohybrid analysis the FATC domain of Mec1 was required for association with the RPA components Rfa1 and Rfa2 [26]. In vivo, the FATC domain of ATM and Tip60 (the mammalian homolog of the NuA4 component Esa1) interact, though this may be indirect [22,27]. Consistent with the mutagenesis analysis of Moritia et al. [24], Lempiäinen and Halazonetis [16] suggest the FATC domain interacts with and regulates the activity of the kinase domain.

Nonsense mediated decay (NMD) is a cellular surveillance mechanism present in all eucaryotes that scans for premature stop codons on mRNAs [28,29]. The process is coupled to translation, and results in degradation of potentially deleterious transcripts [30-32]. Premature stop codons can arise through errors in transcription by RNA Polymerase II, failure or inaccurate removal of introns, inaccurate translational starts, ribosomal frameshifting, RNA editing, or errors within the genomic DNA. The mechanism of NMD varies in different organisms, with the molecular details still being determined [33]. In yeast, one model suggests that NMD is triggered if the mRNA binding protein Hrp1 is bound to a downstream sequence element(s) (DSE) when the ribosome encounters a stop codon [34-36]. The DSE is 5' of the native stop codon, with Hrp1 normally being displaced by the passing ribosome. A second model, the faux (false) 3' UTR model, postulates that the length of the 3' untranslated region resulting from a premature stop codon prevents the normal interactions that occur between the ribosome and poly (A) binding protein during the termination of translation. In the absence of these interactions the NMD factors associate with the ribosome, which in turn results in mRNA decay [37].

The yeast NMD surveillance complex consists of three proteins, Upf1/Nam7, Upf2/Nmd2, and Upf3 (for simplicity referred to as Upf1, Upf2 and Upf3, respectively). Mutations in any of the NMD proteins increase translational read-through and stabilize mRNA containing premature stop codons [30,38-43]. Upf1, an ATP dependent RNA helicase $[41,44]$ is the central component of the pathway, whereas Upf2 and Upf3 regulate Upf1 [42,45]. In metazoans, Upf1 is further regulated by phosphorylation/ dephosporylation [28]. The kinase involved is the PIKK family member SMG-1 $[45,46]$.

In addition to removing aberrant transcripts, the NMD pathway plays a significant role in the control of gene expression [47]. Microarray analyses indicate that approximately $10 \%$ of yeast genes are affected by loss of NMD; most showing increased levels [48-50]. Approximately half of the changes are the result of direct regulation by NMD [50]. Some of the effects on translational readthrough are due to increased expression of the magnesium transporter Alr1p and the elevated cellular magnesium [51]. Other regulatory functions may arise through programmed ribosomal frameshifting, and altered translational start site selection [52-55].

To identify the genetic network in which Tra1 is involved, we selected for second site suppressors that allow growth of strains with the tra1-L3733A allele on media containing ethanol. An opal mutation at codon 165 of upf 1 was identified. Suppression was likely the result of loss of NMD since deletion of upf1, upf 2 or upf 3 conferred growth of strains containing tra1-L3733A. Suppression was specific for mutations to TRA1; phenotypes arising from deletions of SAGA or NuA4 components were not suppressed. Since deletion of upf 1 only reversed the transcriptional defects of the tra 1 alleles at a subset of affected promoters, and these same tra 1 alleles did not affect NMD, we conclude that loss of NMD suppresses the TRA1 mutations through crosstalk and/or partial overlap of their regulatory networks.

\section{Results}

The FATC domain of Tra1 is critical to the protein's function. Mutation of leucine 3733 to alanine results in temperature sensitivity and slow growth in media containing ethanol, Calcofluor white or rapamycin [23]. These phenotypes provide a tool to probe the genetic network in which TRA1 is connected. We selected for extragenic suppressors of the ethanol sensitivity of CY4018, a strain disrupted for the genomic tra1 but viable due to tra1-L3733A on a URA3 centromeric plasmid. Approximately $10^{8}$ cells were plated onto YPD plates containing $4 \%$ ethanol. Forty-three colonies were 
isolated for further analysis. Each was retested for the suppression after colony isolation, and then examined for whether the mutation was located on the tra1-L3733A containing-plasmid by plasmid shuffling. Eleven strains with extragenic mutations that partially suppressed the slow growth due to tra1-L3733A were identified. The growth of these strains on YPD media and YPD containing $4 \%$ ethanol is shown in Figure 1a. The strains with the tra1-L3733A suppressor alleles (tentatively termed es 2 , es 12 , es35 etc.) were mated with the MAT $\alpha$ tra1L3733A strain CY5522 to determine if the suppressor mutations were dominant or recessive. Figure 1b shows the analysis for CY5579 (es2), CY5584 (es38), and CY5587 (es41). The diploid strains grew slowly under selective conditions, indicating that the suppressor alleles act recessively. Similarly each of the additional es alleles was recessive. Complementation groups were analyzed through crosses of the es containing strains. As shown in Figure 1c, the diploid crosses of es 2 with es 38 , and es 41 , grew poorly on media containing $4 \%$ ethanol, in contrast to the homozygous diploid containing es 2 . In this way three complementation groups were identified amongst the eleven strains isolated in the screen. One complementation group contained uniquely es 2 ; a second group contained uniquely es35. The third complementation group contained the remaining nine alleles, including es38 and es41. A random spore analysis indicated that the ethanol resistance for the es2, es35 and es 38 strains (representing each complementation group) segregated $2: 2$ suggesting that a single gene was the cause of suppression.

To determine the identity of the suppressor alleles for the es 2 and es38/es41 complementation groups, we compared the genome sequence for each of the three strains

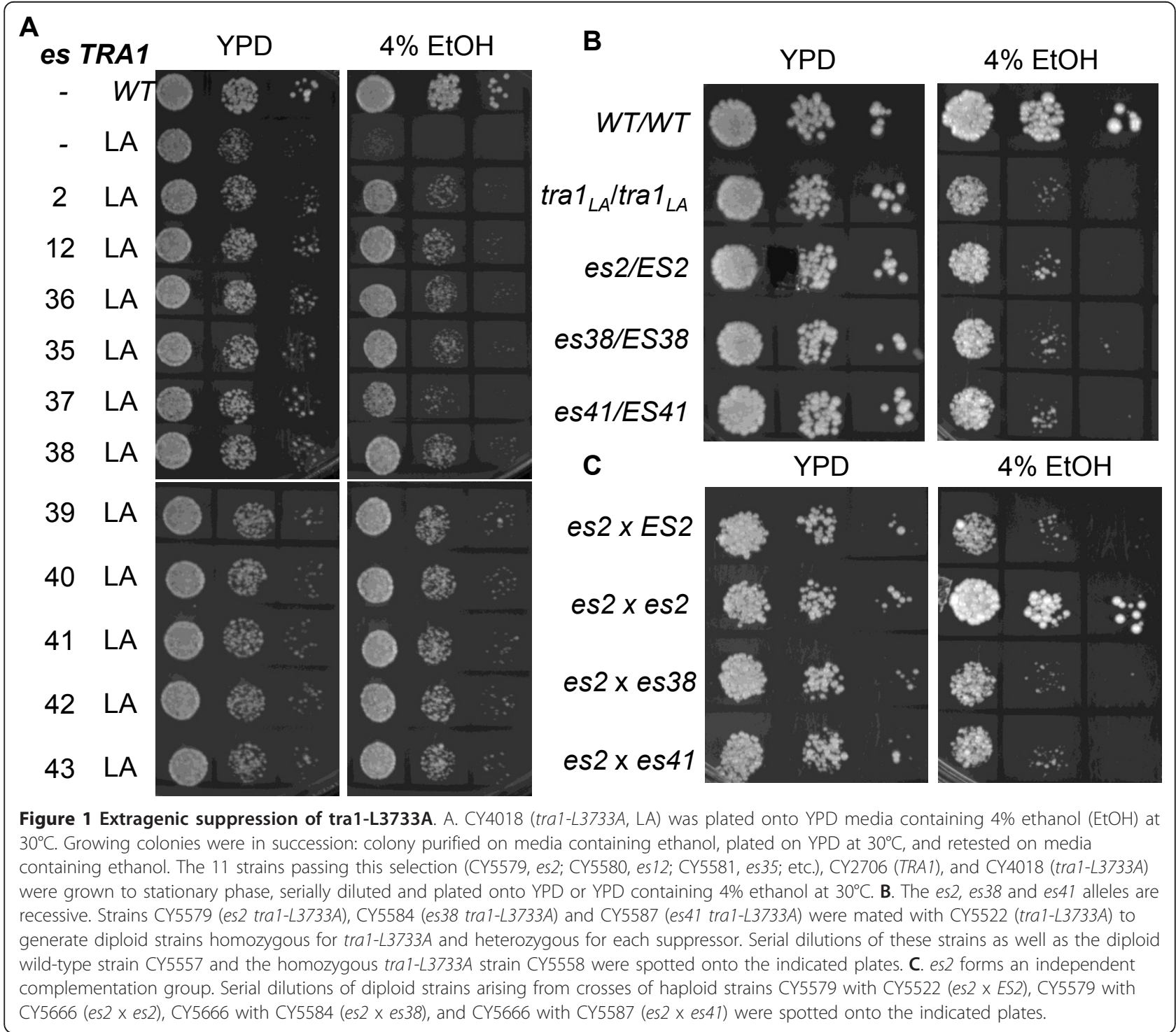


relative to the parent CY4018. (The third complementation group was not analyzed.) Libraries were prepared and genomic sequencing performed using the ABI SOLiD 4.0 platform at the Centre for Applied Genomics at The Hospital for Sick Children (Toronto, Canada). Approximately 50 million reads were obtained for each sample of which $60 \%$ mapped to the reference genome from the Saccharomyces Genome Database. Polymorphisms not found in CY4018 or the other complementation group, were analyzed by visual inspection of the sequencing reads. A causative mutation could not be identified within coding or noncoding sequences for the es38/es41 complementation group. The es 2 strain contained an opal mutation at tryptophan codon 165 of UPF1, truncating the 971-residue protein. To confirm that this allele, now designated $u p f 1_{1-}$ 164, was responsible for the suppression of tra1-L3733A,

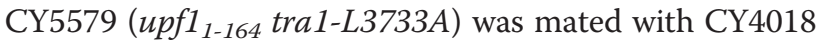
(tra1-L3733A), sporulated, and the UPF1 alleles in 8 unrelated spore colonies, four exhibiting slow growth and four fast growth, were isolated by PCR and sequenced. The four spore colonies growing slowly on $4 \%$ ethanol contained wild-type UPF1, whereas the fast growing spore colonies contained upf1 1 164.

In S. cerevisiae, Upf1 is one of three proteins acting in the NMD surveillance complex, the others being Upf2 and Upf3. To determine if loss of this process was responsible for suppression of tra1-L3733A, we analyzed the growth of strains deleted for upf1, upf 2 or upf 3 in media containing $6 \%$ ethanol and at $37^{\circ} \mathrm{C}$. As shown in Figure 2A, deletion of any of the components of the NMD surveillance complex partially suppressed the slow growth due to tra1-L3733A. Though not documented as a target of NMD, it is possible that loss of NMD suppresses the tra1-L3733A allele by increasing the cellular concentration of the protein. We therefore constructed strains that contain an integrated copy of Flag ${ }^{5}$-tagged Tra1 or Tra1-L3733A, and examined expression in the presence or absence of upf1 by Western blotting of cell extracts (Figure 2B). The expression of the integrated Flag ${ }^{5}$-Tra1-L3733A is similar to the wild-type protein (compare lanes 1 and 3). Disruption of upf1 slightly increased expression of Tra1-L3733A (compare lanes 3 and 6). We estimate this increase to be less than $10 \%$, and suggest that it is not sufficient to account for the suppression.

We next addressed the allele specificity of the suppression. Alteration of the terminal phenylalanine of tra1 to alanine results in slow growth in media containing ethanol. A strain deleted for upf1 and containing tra1F3744A was constructed and its growth compared to the single mutant strains (Figure 3a). Deletion of upf1 suppressed the slow growth due to tra1-F3744A, at least to the same extent as for tra1-L3733A. Deletion of upf1 also suppressed slow growth at $37^{\circ} \mathrm{C}$ and on media containing $6 \%$ ethanol caused by tra1-SRR3413, a triple alanine scanning mutation to residues $3,413-3,415$ within the PI3K domain ([17]; Figure 3b). Deletions of other components of the SAGA and NuA4 complexes were then examined (Figure $3 \mathrm{c}$ and $3 \mathrm{~d}$ ). Deletion of ada2 results in slow growth on media containing ethanol; however, unlike the tra 1 mutations, the slow growth caused by ada2 $\Delta$ was not suppressed by upf1 1 (Figure 3c). Disrupting the NuA4 components Eaf3 or Eaf7 results in slow growth at $35^{\circ} \mathrm{C}$ in media containing $6 \%$ ethanol. Deletion

\begin{tabular}{l}
\hline A \\
TR733A upf1 \\
TRA1 upf3
\end{tabular}




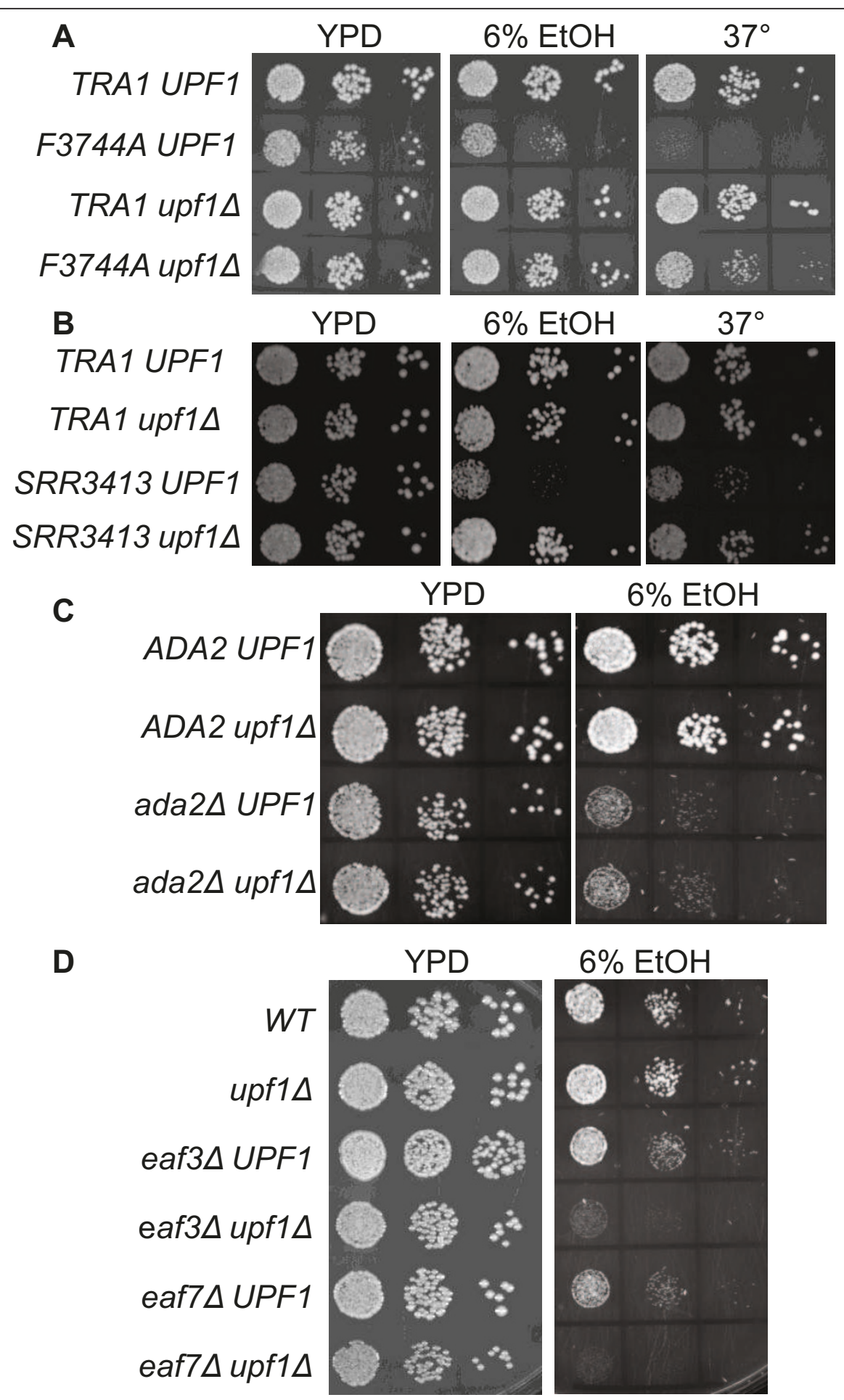

Figure 3 Suppression by upf $1 \Delta$ is specific for mutations within the FATC domain of Tra1. A. upf1 $\triangle$ suppression of tra1-F3744A. Serial dilutions of CY4353 (TRA1 UPF1), CY4350 (tra1-F3744A UPF1), CY5932 (TRA1 upf1 A), and CY6030 (tra1-F3744A upf1 4 ) were spotted onto YPD at $30^{\circ}$ $\mathrm{C}$ or $37^{\circ} \mathrm{C}$, or YPD containing $6 \%$ ethanol at $30^{\circ} \mathrm{C}$. B. upf1 $\triangle$ suppression of tra1-SRR3413. Serial dilutions of BY4742 (TRA1 UPF1), CY5932 (TRA1 upf1 1 ), CY2200 (tra1-SRR3413 UPF1), and CY6111 (tra1-SRR3413 upf1 $\Delta$ ) were spotted onto YPD at $30^{\circ} \mathrm{C}$ or $37^{\circ} \mathrm{C}$, or YPD containing $6 \%$ ethanol at

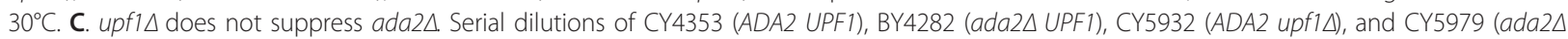
upfi $\Delta$ ) haploids were spotted onto the indicated YPD plates. D. upf1 $\Delta$ does not suppress eaf3 $\Delta$ or eaf7 $\triangle$ Serial dilutions of CY4353 (WT), CY5932

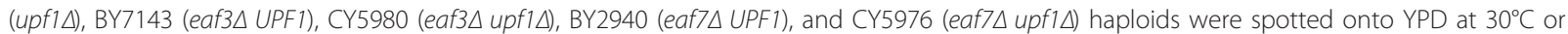
YPD containing $6 \%$ at $35^{\circ} \mathrm{C}$. 
of upf1 did not suppress this phenotype for either the eaf $3 \Delta$ or eaf $7 \Delta$ strains (Figure $3 d$ ). In fact synthetic slow growth was observed on plates containing $6 \%$ ethanol for the double mutant strains. This latter result agrees with the synthetic slow growth reported for mutations of esa 1 and eaf7 with upf1 and upf3, respectively [56,57].

Alterations to the FATC domain cause slow growth in a number of conditions [23]. We analyzed which of these in addition to the suppression of ethanol and temperature sensitivity are suppressed by $u p f 1 \Delta$. As shown in Figure 4, deletion of upf1 suppressed the slow growth resulting from tra1-F3744A when galactose is the carbon source, when phosphate is depleted, and when phleomycin (a DNA damaging agent) is present in the media. In contrast deletion of upf1 did not suppress slow growth due to tra1F3744A in the presence of the cell wall destabilizing agent Calcofluor white, and only had a modest effect with rapamycin. The latter was particularly interestingly, given that deletion of upf1 in the wild-type TRA1 background decreased sensitivity to rapamycin (compare TRA1 UPF1 with TRA1 upf1 1 ).

We next addressed whether disruption of upf1 would reverse the transcriptional defects caused by the TRA1 mutations. Expression of two lac $Z$ promoter fusions was examined: PHO5-lacZ and GAL10-lacZ. tral-L3733A and tra1-F3744A decreased activated expression of PHO5lac $Z$ to approximately one-third of the wild-type level (Figure 5a). Interestingly, the strain containing a disruption of upf1 in the context of wild-type TRA1 also showed decreased expression (approximately 2 -fold). Furthermore, disruption of upf1 in the context of either tral-L3733A or tra1-F3744A did not restore transcription. As shown in Figure 5b expression of GAL10-lacZ was also reduced by tral-L3733A and tra1-F3744A, but in contrast to PHO5-lacZ not by deletion of upf1. In addition, at GAL10 the transcriptional defect due to the tral alleles was partially reversed by upf1 $\Delta$. Together these results suggest that in some, but not all, cases disruption of upf1 may suppress tra1-induced phenotypes by regulating transcription (most likely indirectly) of common genes.

Our previous studies with TRA1 have linked phenotypes resulting from its mutation with transcriptional change $[17,23]$. The observation that disrupting upf1 did not restore transcription in all cases, suggested two models for how loss of NMD might suppress the FATC domain mutations. The first predicts a direct link between NMD and Tra1. If Tra1 is a negative regulator of NMD, Tra1L3733A might increase NMD, decreasing the level of certain mRNA transcripts, which in turn could cause growth-related phenotypes. Loss of the NMD pathway would reverse the effect. The interaction between SAGA component Sgf29 and Upf1 [58], and the phosphorylation of Upf1 by the PIKK member SMG-1 in metazoans $[45,46,59]$, are consistent with the possibility of direct regulation. The second model predicts a less specific interaction between Tra1 and NMD. The tra1 mutations through its action in SAGA, NuA4 or independently [13] alter expression of a set of genes. Some of these genes, or genes with epistatic relationships, may be regulated through mRNA turnover and/or translational readthrough by processes involving NMD. This possibility is enhanced by the scope of both networks and their generally reciprocal nature. By eliminating NMD the expression of genes that directly or indirectly intersect in the pathways may return to near normal, effectively compensating for diminished Tra1 activity. To differentiate between these models, we analyzed whether tral-L3733A alters NMD. We constructed a $P G K 1-l a c Z$ fusion $\left(P G K 1_{f_{s}}\right.$ lacZ; Figure 6a) frameshifted at codon 166 and including those sequences required for NMD, -544 to 891 [34,60]. Previous mRNAseq experiments have indicated that PGK1 expression in YPD media is relatively unaffected by mutations within the FATC domain of Tra1 [23]. Deletion of upf1 results in a 5 -fold increase in expression of $\beta$-galactosidase from the $P G K 1_{f_{s}}$-lacZ fusion in comparison to a wild-type UPF1 strain (Figure 6b), verifying the use of this construct to monitor NMD. Indicative of Tra1 not having a direct role

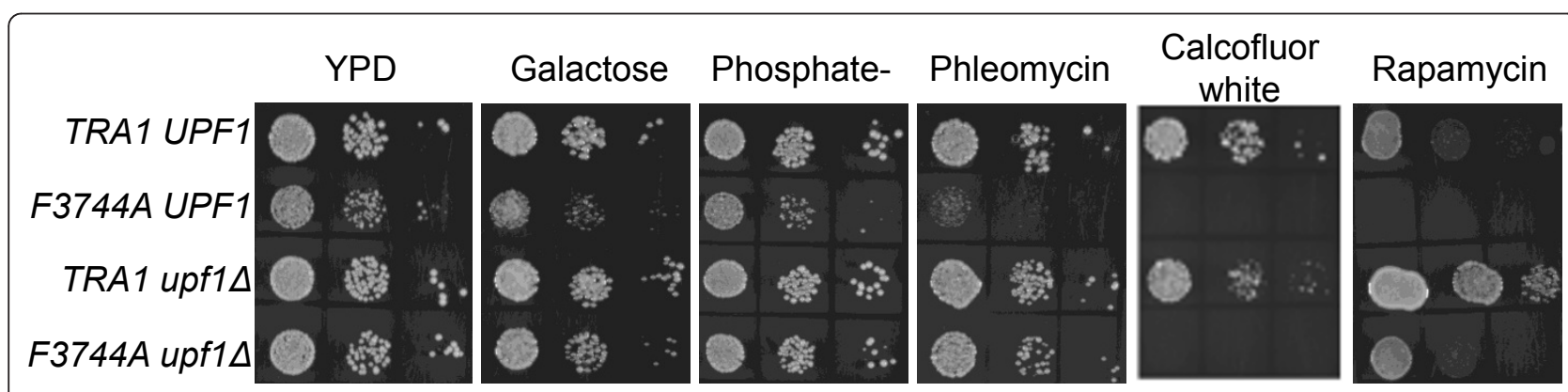

Figure 4 Phenotypes of TRA1-F3744A suppressed by upf14. Serial dilutions of yeast strains CY4353 (TRA1 UPF1), CY4350 (tra1-F3744A UPF1), CY5932 (TRA1 upf1 $\Delta$ ), and CY6030 (tra1-F3744A upf1 $\Delta$ ) haploids were spotted onto YPD, YP plus 2\% galactose, YPD depleted of phosphate, or YPD containing $1 \mu \mathrm{g} / \mathrm{mL}$ phleomycin, $10 \mu \mathrm{g} / \mathrm{mL}$ Calcofluor white, or $2 \mathrm{nM}$ rapamycin. 


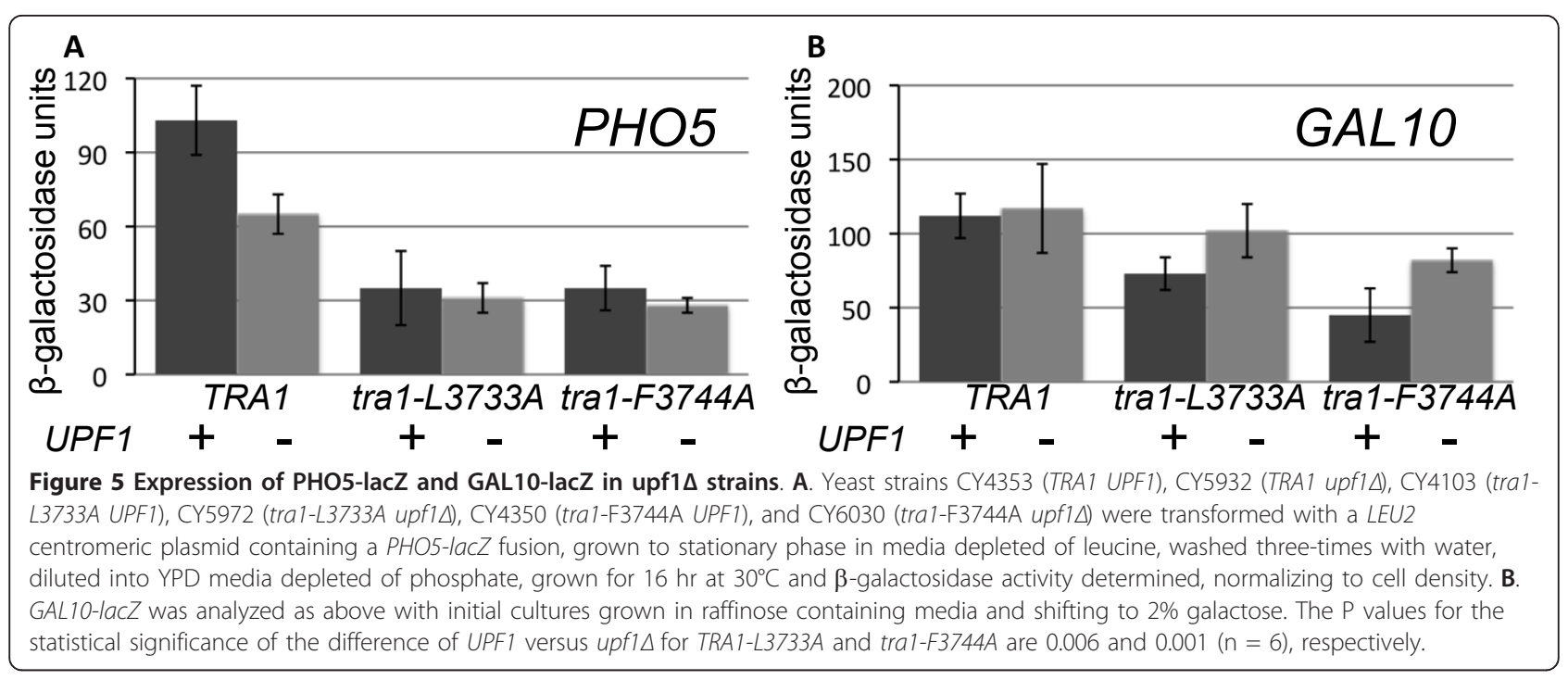

in NMD, expression of $P G K 1_{f s}-l a c Z$ was unaffected by tral-L3733A. In light of this result and the broad role for NMD in gene expression, we thus favor a model whereby deletion of NMD suppresses the tra1 alleles through its reciprocal action on an overlapping set of genes.

\section{Discussion}

We have identified a genetic interaction between components of the nonsense mediated decay pathway and tra1, through random selection for mutations that suppress the ethanol sensitivity of a tra1-L3733A strain. Our initial selection identified a nonsense mutation at codon 165 of UPF1. Similar suppression was found with deletions of upf1, upf 2 and upf3 indicating that loss of nonsense mediated decay was the likely cause. Our study demonstrates a relationship between the Tra1 and NMD regulatory networks, and further emphasizes the general importance of NMD in gene expression.

The suppression mediated by deletion of upf1 was specific for certain phenotypes arising from tra1 mutations. Slow growth due to high temperature, ethanol, low phosphate, galactose as the primary carbon source, and phleomycin was suppressed. Slow growth due to rapamycin or Calcofluor white was not. The suppression mediated by upf1 1 was also specific for mutations within TRA1, not suppressing deletions of the SAGA component Ada2 or the NuA4 components Eaf3 or Eaf7. In the case of the latter two disruptions, synthetic slow growth was observed.

We propose the suppression of tra1-L3733A and tra1F3744A caused by loss of NMD is the result of crosstalk and/or direct overlap in the networks regulated by these genes. In this model, altered (most often decreased)

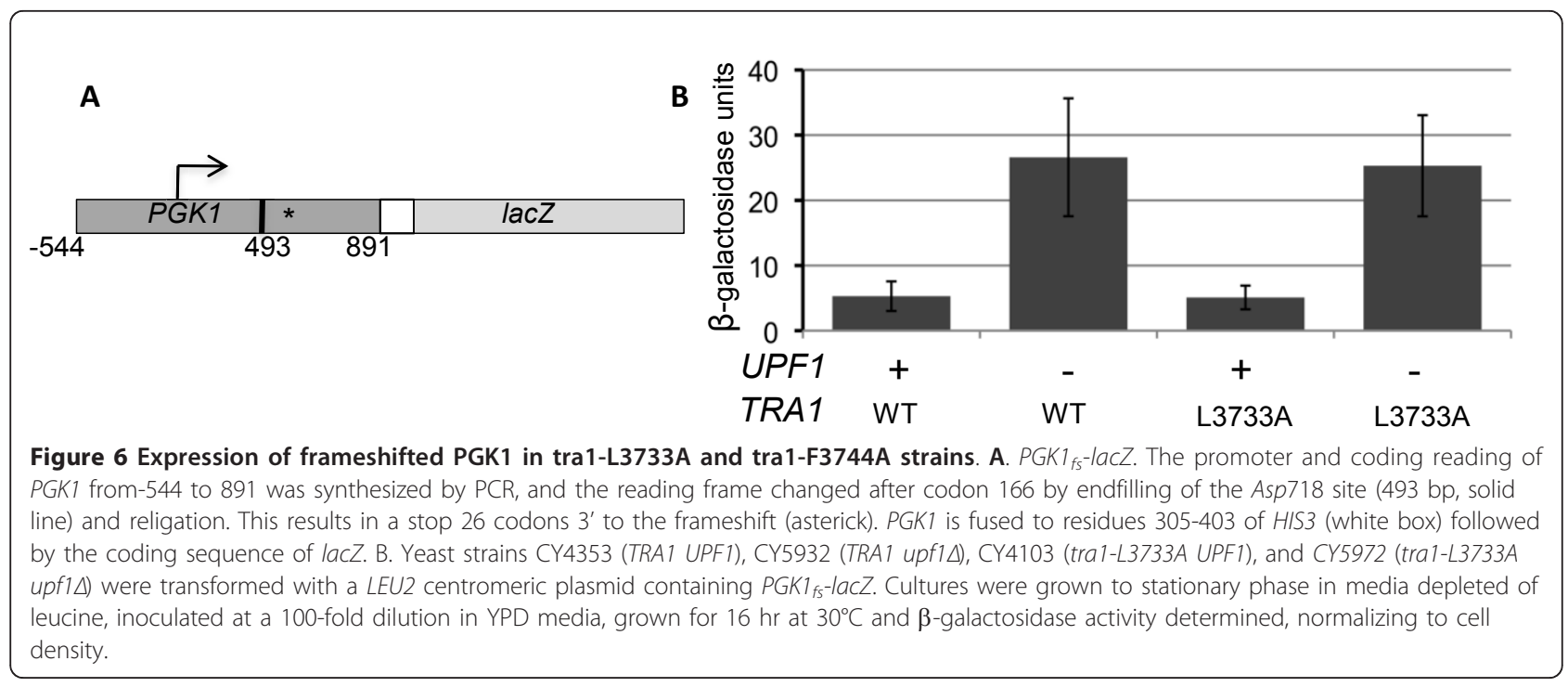


expression resulting from the tra1 mutations would be partially reversed by reducing mRNA turnover (or enhancing translational readthrough) in the NMD deficient backgrounds. Also along this line, a gene regulated by NMD may encode a protein that directly or indirectly regulates some of the functions of Tra1. Our reasons for preferring this indirect mechanism for suppression are the following. First, consistent with this model nonsense mediated decay has a broad role in gene regulation. Some of NMD's roles relate to the removal of aberrant transcripts that have acquired nonsense codons. Other roles relate to control mechanisms that utilize the pathway to remove mRNAs that would otherwise be functional. As such NMD influences approximately $10 \%$ of yeast genes $[48,49]-$ likely an underestimate of the extent of its control as this is in rich media. Clearly the breadth of the NMD effect indicates that NMD is of global importance in yeast regulatory pathways, not only affecting aberrant transcripts. The majority of genes are upregulated in response to loss of NMD; this contrasts to the generally more prevalent decreased expression observed upon mutation of tra1 $[17,23]$. Thus the prevalence of genes affected and reciprocal nature of loss of NMD and Tra1 could result in their neutralization in a double mutant background. Indeed, it is the scope of NMD that likely explains why its loss can also suppress mutations of other globally important yet functionally diverse factors required for gene expression (for example: TAF6, TAF9 and RAP1 [57], PAF1 [61], and BRE1 [62]).

This indirect model for suppression accommodates the finding that only a subset of tra1-L3733A phenotypes is suppressed by loss of NMD. Suppression would require that Tra1 and NMD regulate key genes responsible for the phenotype (also see below). Similarly, specificity for TRA1 mutations may be accounted for if other NuA4 and/or SAGA components influence genes to an extent that is not sufficiently reversed by NMD. Finally, the finding that loss of NMD affects promoter-dependent events of some tra1-effected genes (for example GAL10) but not others (for example, $P H O 5$ ) is more consistent with an indirect mechanism for suppression that could act through distinct genes and/or steps in gene expression, rather than by restoring Tra1 function.

Alternative models for suppression by upf1 $\Delta$ are possible if Tra1 were involved in NMD. The finding that tra1L3733A and tra1-F3744A did not alter expression of an internally frame-shifted $P G K 1$ reporter plasmid, suggests that Tra1 is not directly involved in NMD. The lack of direct relationship between Tra1 and NMD is consistent with Tra1 acting in the nucleus, whereas in S. cerevisiae NMD is primarily a cytoplasmic process regulating posttranscriptional events [63].

We have not pinpointed the genes whose regulation by NMD allows suppression of the phenotypes caused by
tra1-L3733A. Because of epistatic relationships, the key genes affected by tra1-L3733A and NMD may not be identical. It is also possible that small changes in multiple target genes could cause suppression; this would make identification of relevant targets difficult. Expression screening of mRNAs to detect changes in profiles may be complicated because the genes are likely stress induced, and will differ from condition to condition. Moreover, some aspects of NMD relate specifically to translation, and will not be seen by RNA profiling. Nonetheless, we have compared gene expression profiles in YPD media for tra1-L3733A [23] and upf1 0 [49] strains. Of the 79 genes with reduced expression due to tra1L3733A (twofold or greater), six display increased expression of twofold or greater with upf1 1 (one has decreased expression). This ratio, given that it approximates the $10 \%$ of the genome regulated by NMD, does not support a specific overlap in the pathways, however it does emphasize the generally reciprocal nature of Tra1 and NMD. The six genes with reciprocal changes in expression are YBL107C, YER187W, MIP6 (YHR015W), JMN1 (YMR294W), YNR071C and YOL014W. Of these only MIP6 and JMN1 have characterized functions. MIP6 is of potential relevance since it encodes a protein with putative RNA binding motifs, and was identified in a twohybrid analysis as interacting with the Mex67, an mRNA export factor [64].

When expressed on a centromeric plasmid from the DED1 promoter, Tra1-L3733A is less abundant than the wild type protein [23]. We do not observe this decrease when FATC mutations are integrated into the genome. For this reason the functional experiments performed in this analysis were with genomically encoded tra1-L3733A and tra1-F3744A. Based on the recent results of Stirling et al. [65], who show a link between chromosome instability and components of the ASTRA complex, we believe that the plasmid versions may be less well expressed due to decreased stability of the plasmid for the mutant versions of tra1.

In a recent independent selection for suppressors of tra1-F3744A, we identified two alleles of the ASTRA component Tti2 (Genereaux et al. Genetics, in press). The tti2 alleles also suppress tra1-L3733A, but not deletions of components of SAGA or NuA4 components. The tti2 alleles, unlike $u p f 1_{1-164}$, acted dominantly. This as well as complementation experiments with TTI2 (not shown) suggests that es38/41 and es35 represent additional independent suppressor alleles.

\section{Conclusion}

We have demonstrated a genetic interaction between TRA1 and genes of the nonsense mediated decay pathway. In a recessive manner, deletion of upf 1 partially suppressed the growth related defects of tra1-L3733A, 
tra1-F3744A and tra1-SRR3413, mutations within the FATC and PI3K domains. The suppression was specific for TRA1 mutations; no effect was seen for deletions of other SAGA or NuA4 components. A subset of phenotypes attributable to the FATC mutations was suppressed; furthermore, not all transcriptional defects were reversed by deletion of upf1. We suggest that the suppression relates to the breadth and overlapping, yet generally reciprocal nature of the gene regulatory pathways in which Tra1 and the NMD components are involved.

\section{Methods}

\section{Yeast strains and growth}

Strains for selection of suppressor mutations are derivatives of KY320 ([66]; see Table 1) and the isogenic MAT $\alpha$ strain CY4413. CY1021 contains a genomic disruption of tra 1 and is maintained by a plasmid copy of myc-tagged TRA1 expressed from the DED1 promoter [2]. CY3003 [23] and CY4018 were obtained from CY1021 by plasmid shuffling and contain myc ${ }^{9}$-tagged tra1-L3733A expressed from the DED1 promoter on YCplac22 [67] or a $U R A 3$ centromeric plasmid (YCplac22u) derived from YCplac22 by switching TRP1 to URA3, respectively [68]. CY5522 is the MAT $\alpha$ equivalent of CY4018 and was generated by mating CY4413 with CY4018. After sporulation, a MAT $\alpha$ spore colony was isolated that required the plasmid copy of tra1-L3733A for growth. Strains carrying tra1-L3733A and extragenic suppressors (hereafter defined as es alleles) es2 (CY5579), es12 (CY5580), es35 (CY5581), es36 (CY5582), es37 (CY5583), es38 (CY5584), es39 (CY5585), es40 (CY5586), es41 (CY5587), es42 (CY5588), and es43 (CY5750) were derived from CY4018 using the selection scheme described below. CY5666 (es2), CY5758 (es38), and CY5603 (es41) are MAT $\alpha$ equivalents of CY5579, CY5584, and CY5587, respectively, and were made after mating with CY5522. MAT $\boldsymbol{\alpha}$ spore colonies carrying the suppressor were selected based on their ability to grow at high temperature and on plates containing 4\% ethanol.

Yeast strains deleted for upf1 (CY5932), upf3 (CY5936) and upf2 (CY5934) were derived from the diploid strains, BY46214, BY44702 and BY41905 [71], respectively, by selecting $\mathrm{Kan}^{\mathrm{r}}$ spore colonies. These MATa strains were mated with CY4057 (tra1-L3733A; [23]), to yield after sporulation and selection of $\mathrm{Kan}^{\mathrm{r}} \mathrm{His}{ }^{-}$spore colonies CY5972 (upf1A tra1-L3733A), CY5983 (upf3A tra1L3733A), and CY5996 (upf2A tra1-L3733A). Similarly, CY6030 (upf1 tra1-F3744A) was generated after mating of CY4351 (tra1-F3744A) and CY5932. CY5939 (upf1A:: nat1) was obtained by gene replacement of $\mathrm{Kan}^{r}$ with nat1. Double mutant strains of upf1 $\Delta:$ :nat1 with ada $2 \Delta$ (CY5979), eaf3 (CY5980), and eaf7 (CY5976) were obtained after mating and sporulation of the diploids of crosses of CY5939 with BY4282, BY7143, and BY2940, respectively. CY6111 (tra1-SRR3413 upf1A) was derived after mating of CY2220 [69] and CY5932, and selecting Ura $+\operatorname{Kan}^{\mathrm{r}}$ spore colonies. CY6004, CY6005 contain a TRA1 allele with a N-terminal Flag ${ }^{5}$-tag integrated with a URA3 marker.

Growth comparisons were performed on YP media containing 2\% glucose (YPD) selective plates after 3-5 days at $30^{\circ} \mathrm{C}$ unless stated otherwise. Standard concentrations used for the selections are as follows: $7.5 \mu \mathrm{g} / \mathrm{ml}$ Calcofluor White (Sigma-Aldrich, Inc.), $4 \%$ or $6 \%$ ethanol, $1.0 \mu \mathrm{g} / \mathrm{ml}$ phleomycin (Sigma-Aldrich, Inc.), and $2 \mathrm{nM}$ rapamycin (LC Laboratories, Woburn Ma). We note that the KY320 background is more sensitive to ethanol than the BY4741 background, accounting for the use of either $4 \%$ or $6 \%$ ethanol, respectively.

\section{DNA molecules}

Myc-tagged tra1 alleles on the centromeric TRP1 (YCplac22) or URA3 (YCplac33) plasmids have been described $[17,23]$. PHO5 $(-452$ to +47$)$ and GAL10 (-595 to -245$)$ promoter-lac $Z$ fusions in the LEU2 centromeric plasmid YCp87 have been described [17,72]. The PGK1lacZ fusion with a frameshift mutation (PGK1fs-lacZ) was constructed by synthesizing the gene from -544 to +891 by PCR using oligonucleotides 5'-GCGGATCCACGTGGCCTCTTATCGAG-3' and 5'-CTCAAGCT TCCTTGGTGTTGGCATCAGCAGAG-3', digesting the gene with $A s p 718$, creating blunt ends with the Klenow fragment of DNA polymerase and religation.

\section{Isolation of suppressor strains}

Six cultures of CY4018 were grown overnight in YPD. Approximately 100 million cells were plated onto 200 YPD plates containing $4 \%$ ethanol and incubated at $30^{\circ} \mathrm{C}$ for 5 days. Fast growing colonies were colony purified and retested. YCplac22-tra1-L3733A was transformed into each potential suppressor strain and $Y C_{\text {P }} \operatorname{lac}_{2} 2 u-\mathrm{myc}_{9^{-}}$ tra1-L3733A shuffled out on 5-fluoroorotic acid. Strains that retained their ability to grow on $4 \%$ ethanol were defined as containing extragenic suppressors.

\section{Genomic sequence analysis}

Genomic DNA was prepared from $10 \mathrm{~mL}$ of lyticase treated cells [73]. Approximately $5 \mu \mathrm{g}$ of DNA from each sample was sent to the Centre for Applied Genomics (Toronto, Ontario). DNA library construction and next-generation sequencing using paired-end reads was performed at the Centre. Samples were sequenced using the Applied Biosystems SOLiD 4.0 next-generation sequencing platform. The sequencing was performed in a single lane with multiplexing that included 11 additional unrelated samples. The Saccharomyces cerevisiae genome sequence was downloaded from the Saccharomyces Genome Database (SGD; [74]) on March 24, 2011. Custom Shell and Perl scripts were 
Table 1 Yeast strains

\begin{tabular}{|c|c|c|c|}
\hline $\begin{array}{l}\text { Strain } \\
\text { number }\end{array}$ & Description & TRA1 plasmid & Reference \\
\hline CY1021 & Isogenic to KY320 except tra1 $\Delta$ & YCplac22-myc-TRA1 & [2] \\
\hline CY2706 & Isogenic to CY1021 & YCplac22-my $c_{9}-T R A 1$ & [23] \\
\hline CY3003 & Isogenic to CY1021 & $\begin{array}{l}\text { YCplac22-myc -tra1- } \\
\text { L3733A }\end{array}$ & [23] \\
\hline CY4018 & Isogenic to CY1021 & $\begin{array}{l}\text { YCplac22u-myco-tra1- } \\
\text { L3733A }\end{array}$ & This study \\
\hline CY5522 & Isogenic to CY3003 except MAT $\alpha$ & $\begin{array}{l}\text { YCplac22-myco-tra1- } \\
\text { L3733A }\end{array}$ & This study \\
\hline CY5557 & Diploid cross of CY2706 and CY4413 & YCplac22-myc 9 -TRA1 & This study \\
\hline CY5558 & Diploid cross of CY4018 and CY5522 & $\begin{array}{l}\text { YCplac22-myc9-tra1- } \\
\text { L3733A }\end{array}$ & This study \\
\hline CY5579 & isogenic to CY4018 except es2 (upf1 $\left.1_{1-164}\right)$ & $\begin{array}{l}\text { YCplac22u-myc }- \text { tra1- } \\
\text { L3733A }\end{array}$ & This study \\
\hline CY5580 & isogenic to CY4018 except es 12 & $\begin{array}{l}\text { YCplac22u myc } 9 \text {-tra 1- } \\
\text { L3733A }\end{array}$ & This study \\
\hline CY5581 & isogenic to CY4018 except es35 & $\begin{array}{l}\text { YCplac22u myc } 9 \text {-tra1- } \\
\text { L3733A }\end{array}$ & This study \\
\hline CY5582 & isogenic to $\mathrm{CY} 4018$ except es36 & $\begin{array}{l}\text { YCplac22u myc } \text {-tra 1- } \\
\text { L3733A }\end{array}$ & This study \\
\hline CY5583 & isogenic to CY4018 except es37 & $\begin{array}{l}\text { YCplac22u myc9-tra1- } \\
\text { L3733A }\end{array}$ & This study \\
\hline CY5584 & isogenic to CY4018 except es38 & $\begin{array}{l}\text { YCplac22u myc-tra1- } \\
\text { L3733A }\end{array}$ & This study \\
\hline CY5585 & isogenic to CY4018 except es39 & $\begin{array}{l}\text { YCplac22u-myco-tra1- } \\
\text { L3733A }\end{array}$ & This study \\
\hline CY5586 & isogenic to CY4018 except es 40 & $\begin{array}{l}\text { YCplac22u-myc9-tra1- } \\
\text { L3733A }\end{array}$ & This study \\
\hline CY5587 & isogenic to CY4018 except es 41 & $\begin{array}{l}\text { YCplac22u-myc-tra1- } \\
\text { L3733A }\end{array}$ & This study \\
\hline CY5588 & isogenic to CY4018 except es42 & $\begin{array}{l}\text { YCplac22u-myc }- \text {-tra1- } \\
\text { L3733A }\end{array}$ & This study \\
\hline CY5750 & isogenic to CY4018 except es43 & $\begin{array}{l}\text { YCplac22u-myco-tra1- } \\
\text { L3733A }\end{array}$ & This study \\
\hline CY5666 & Isogenic to CY5522 except es2 (upf1 1-164 ) & $\begin{array}{l}\text { YCplac22-myc-tra1- } \\
\text { L3733A }\end{array}$ & This study \\
\hline CY5758 & Isogenic to CY5522 except es38 & $\begin{array}{l}\text { YCplac22-myc }- \text { tra1- } \\
\text { L3733A }\end{array}$ & This study \\
\hline CY5603 & Isogenic to CY5522 except es41 & $\begin{array}{l}\text { YCplac22-myc9-tra1- } \\
\text { L3733A }\end{array}$ & This study \\
\hline CY5688 & Isogenic to CY2706 except es2 (upf1 $\left.1_{1-164}\right)$ & YCplac22u-myc $c_{9}-T R A 1$ & This study \\
\hline CY5690 & Isogenic to CY2706 except es38 & YCplac22u-myc-TRA1 & This study \\
\hline CY5691 & Isogenic to CY2706 except es41 & YCplac22u-myc-TRA1 & This study \\
\hline KY320 & MATa ura3-52 ade2-101 trp1- $\triangle 1$ lys2-801 his3-L200 leu2::PET56 & & {$[66]$} \\
\hline CY4413 & 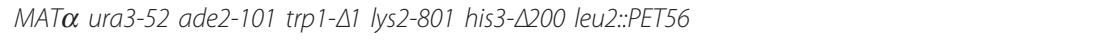 & & \\
\hline CY2222 & 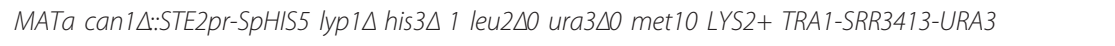 & & [69] \\
\hline BY4741 & 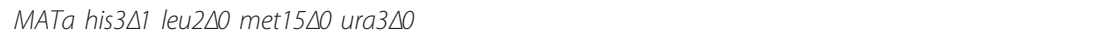 & & [70] \\
\hline BY4742 & 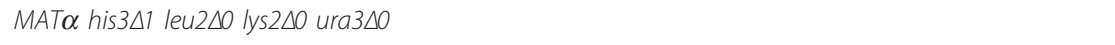 & & [70] \\
\hline BY2940 & 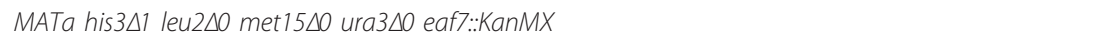 & & [70] \\
\hline BY4282 & 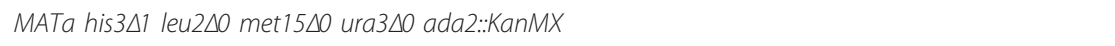 & & [70] \\
\hline BY7143 & 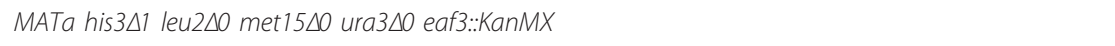 & & [70] \\
\hline BY41905 & 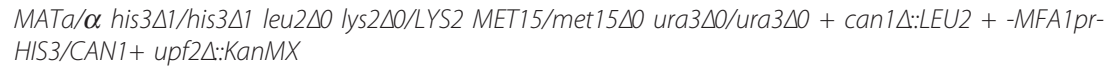 & & [71] \\
\hline BY44702 & 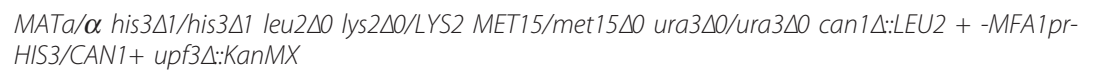 & & [71] \\
\hline BY46214 & 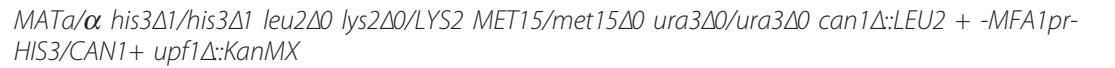 & & [71] \\
\hline
\end{tabular}


Table 1 Yeast strains (Continued)

\begin{tabular}{|c|c|c|}
\hline CY4350 & 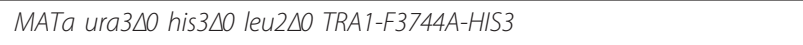 & [23] \\
\hline CY4353 & MATa ura3 $\triangle 0$ his3 $\triangle 0$ leu2 $\triangle 0$ TRA1-HIS3 & [23] \\
\hline CY4103 & 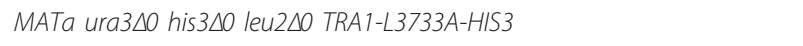 & {$[23]$} \\
\hline CY5932 & 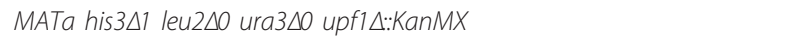 & This study \\
\hline CY5934 & 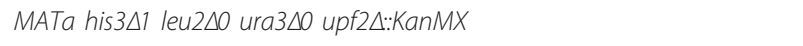 & This study \\
\hline CY5936 & 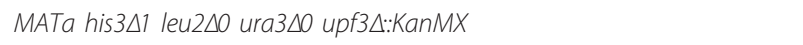 & This study \\
\hline CY5937 & 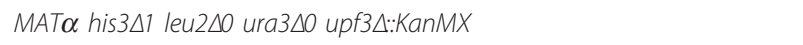 & This study \\
\hline CY5938 & 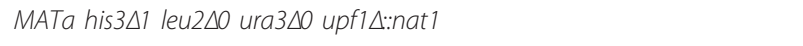 & This study \\
\hline CY5939 & 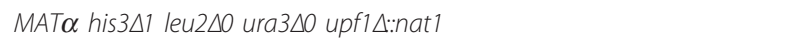 & This study \\
\hline CY5940 & 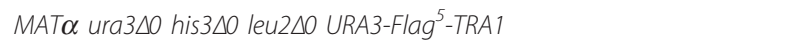 & This study \\
\hline CY5967 & 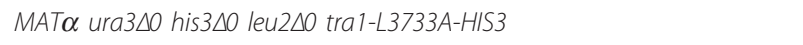 & This study \\
\hline CY5968 & 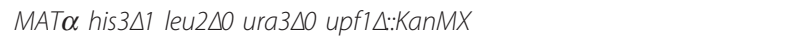 & This study \\
\hline CY5972 & 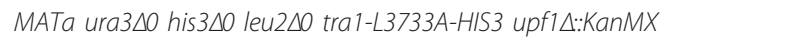 & This study \\
\hline CY5976 & 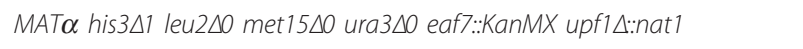 & This study \\
\hline CY5979 & 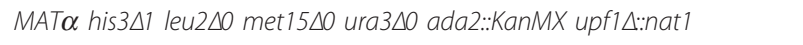 & This study \\
\hline CY5980 & 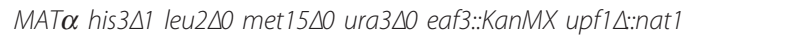 & This study \\
\hline CY5983 & 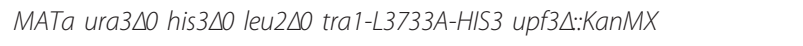 & This study \\
\hline CY5996 & MATa ura3 $\triangle 0$ his3 $\Delta 0$ leu2 $\triangle 0$ tra1-L3733A-HIS3 upf2A:KanMX & This study \\
\hline CY6004 & 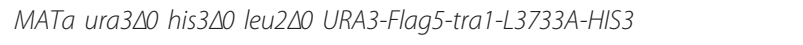 & This study \\
\hline CY6005 & 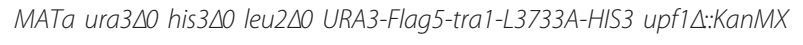 & This study \\
\hline CY6030 & 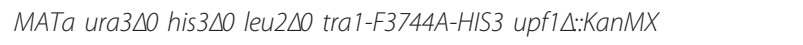 & This study \\
\hline CY6102 & 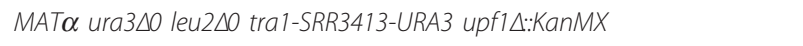 & This study \\
\hline
\end{tabular}

written for the sequencing analysis. The program Bowtie [75], allowing up to three mismatches per read, was used to map the colorspace reads to each chromosome of the yeast genome and obtain mapped reads in SAM format (Sequence Alignment/Map; [76]). The VCF (variant call format) from SAMtools [76] was used to obtain a raw list of polymorphisms from the mapped reads. Those reads with a Phred quality score below 20 were eliminated to obtain a filtered list of polymorphisms. A custom Perl script was written to eliminate the background polymorphisms found in wild-type samples.

\section{$\beta$-galactosidase assays}

Yeast strains containing lacZ-promoter fusions were grown to stationary phase in media lacking leucine. Assays with PHO5-lacZ in media depleted of phosphate and GAL10-lacZ in media containing galactose as the sole carbon source were performed as described in Mutiu et al. [17] and Brandl et al. [72], respectively, with o-nitrophenol- $\beta$-D-galactosidase as substrate and normalizing values to cell density. Assay of $P G K 1_{f s}-l a c Z$ was performed similarly in YPD media. Results presented are from a minimum of four replicates with the standard errors indicated.

\section{Western blotting}

Western blotting was performed using PVDF membranes and anti-Flag (M2; Sigma-Aldrich) antibody as described previously [17].

\section{Acknowledgements}

We would like to thank Megan Davey and Stephen Hoke for critically reading the manuscript, Julie Genereaux for technical assistance, Ivan Sadowski for sharing sequencing lanes, and Joe Mymryk for plasmids. This work was supported by CIHR grant MOP10845 to CJB. SK was supported by a National Science and Engineering Research Council of Canada Studentship.

\section{Authors' contributions}

SK and CJB performed the experiments and co-wrote the manuscript. GBG and SK performed the bioinformatics analysis. All authors have read and approved the manuscript.

Received: 6 January 2012 Accepted: 22 March 2012

Published: 22 March 2012

\section{References}

1. Grant PA, Schieltz D, Pray-Grant M, Yates JR, Workman JL: The ATM-related cofactor Tra1 is a component of the purified SAGA complex. Mol Cell 1998, 2:863-867.

2. Saleh A, Schieltz D, Ting N, McMahon SB, Litchfield DW, Yates JR, LeesMiller S, Cole MD, Brandl CJ: Tra1p is a component of the yeast Ada.Spt transcriptional regulatory complexes. J Biol Chem 1998, 273:26559-26565.

3. Allard S, Utley RT, Savard J, Clarke A, Grant P, Brandl CJ, Pillus L, Workman $J$, Côté J: NuA4, an essential transcription adaptor/histone H4 acetyltransferase complex containing Esa1p and the ATM-related cofactor Tra1p. EMBO J 1999, 18:5108-5119.

4. Doyon Y, Selleck W, Lane WS, Tan S, Côté J: Structural and functional conservation of the NuA4 histone acetyltransferase complex from yeast to humans. Mol Cell Biol 2004, 24:1884-1896.

5. Rodriguez-Navarro S: Insights into SAGA function during gene expression. EMBO Rep 2009, 10:843-850.

6. Koutelou E, Hirsch CL, Dent SY: Multiple faces of the SAGA complex. Curr Opin Cell Biol 2010, 22:374-382.

7. Shevchenko A, Roguev A, Schaft D, Buchanan L, Habermann B, Sakalar C, Thomas H, Krogan NJ, Shevchenko A, Stewart AF: Chromatin Central: towards the comparative proteome by accurate mapping of the yeast proteomic environment. Genome Biol 2008, 9:R167. 
8. McMahon SB, Van Buskirk HA, Dugan KA, Copeland TD, Cole MD: The novel ATM-related protein TRRAP is an essential cofactor for the c-Myc and E2F oncoproteins. Cell 1998, 94:363-374.

9. Bhaumik SR, Raha T, Aiello DP, Green MR: In vivo target of a transcriptional activator revealed by fluorescence resonance energy transfer. Genes Dev 2004, 18:333-343.

10. Brown CE, Howe L, Sousa K, Alley SC, Carrozza MJ, Tan S, Workman JL: Recruitment of HAT complexes by direct activator interactions with the ATM-related Tra1 subunit. Science 2001, 292:2333-2337.

11. Fishburn J, Mohibullah N, Hahn S: Function of a eukaryotic transcription activator during the transcription cycle. Mol Cell 2005, 18:369-378

12. Reeves WM, Hahn S: Targets of the Gal4 transcription activator in functional transcription complexes. Mol Cell Biol 2005, 25:9092-9102.

13. Helmlinger D, Marguerat S, Villen J, Swaney DL, Gygi SP, Bahler J, Winston F: Tra1 has specific regulatory roles, rather than global functions, within the SAGA co-activator complex. EMBO J 2011, 30:2843-2852.

14. Abraham RT: PI 3-kinase related kinases: 'big' players in stress-induced signaling pathways. DNA Repair (Amst) 2004, 3:883-887.

15. Lovejoy CA, Cortez D: Common mechanisms of PIKK regulation. DNA Repair (Amst) 2009, 8:1004-1008.

16. Lempiainen $\mathrm{H}$, Halazonetis TD: Emerging common themes in regulation of PIKKs and PI3Ks. EMBO J 2009, 28:3067-3073.

17. Mutiu Al, Hoke SM, Genereaux J, Hannam C, MacKenzie K, JobinRobitaille O, Guzzo J, Côté J, Andrews B, Haniford DB, Brandl CJ: Structure/ function analysis of the phosphatidylinositol-3-kinase domain of yeast tra1. Genetics 2007, 177:151-166.

18. Bosotti R, Isacchi A, Sonnhammer EL: FAT: a novel domain in PIK-related kinases. Trends Biochem Sci 2000, 25:225-227.

19. Perry J, Kleckner N: The ATRs, ATMs, and TORs are giant HEAT repeat proteins. Cell 2003, 112:151-155.

20. Sibanda BL, Chirgadze DY, Blundell TL: Crystal structure of DNA-PKcs reveals a large open-ring cradle comprised of HEAT repeats. Nature 2010, 463:118-121.

21. Knutson BA, Hahn S: Domains of TRA1 important for activator recruitment and transcription coactivator functions of SAGA and NuA4 complexes. Mol Cell Biol 2011, 31:818-831.

22. Sun $Y$, Jiang $X$, Chen S, Fernandes N, Price BD: A role for the Tip60 histone acetyltransferase in the acetylation and activation of ATM. Proc Natl Acad Sci USA 2005, 102:13182-13187.

23. Hoke SM, Mutiu Al, Genereaux J, Kvas S, Buck M, Yu M, Gloor GB, Brandl CJ: Mutational analysis of the C-terminal FATC domain of Saccharomyces cerevisiae Tra1. Curr Genet 2010, 56:447-465.

24. Morita T, Yamashita A, Kashima I, Ogata K, Ishiura S, Ohno S: Distant N- and C-terminal domains are required for intrinsic kinase activity of SMG-1, a critical component of nonsense-mediated mRNA decay. J Biol Chem 2007, 282:7799-7808.

25. Dames SA, Mulet JM, Rathgeb-Szabo K, Hall MN, Grzesiek S: The solution structure of the FATC domain of the protein kinase target of rapamycin suggests a role for redox-dependent structural and cellular stability. $J$ Biol Chem 2005, 280:20558-20564

26. Nakada D, Hirano $Y$, Tanaka $Y$, Sugimoto $K$ : Role of the $C$ terminus of Mec1 checkpoint kinase in its localization to sites of DNA damage. Mol Biol Cell 2005, 16:5227-5235.

27. Sun $Y$, Jiang $X$, Price BD: Tip60: connecting chromatin to DNA damage signaling. Cell Cycle 2010, 9:930-936.

28. Chang YF, Imam JS, Wilkinson MF: The nonsense-mediated decay RNA surveillance pathway. Annu Rev Biochem 2007, 76:51-74.

29. Muhlemann O, Eberle AB, Stalder L, Zamudio Orozco R: Recognition and elimination of nonsense mRNA. Biochim Biophys Acta 2008, 1779:538-549.

30. Wang W, Czaplinski K, Rao Y, Peltz SW: The role of Upf proteins in modulating the translation read-through of nonsense-containing transcripts. EMBO J 2001, 20:880-890.

31. Amrani N, Sachs MS, Jacobson A: Early nonsense: mRNA decay solves a translational problem. Nat Rev Mol Cell Biol 2006, 7:415-425.

32. Hu W, Petzold C, Coller J, Baker KE: Nonsense-mediated mRNA decapping occurs on polyribosomes in Saccharomyces cerevisiae. Nat Struct Mol Biol 2010, 17:244-247.

33. Brogna S, Wen J: Nonsense-mediated mRNA decay (NMD) mechanisms. Nat Struct Mol Biol 2009, 16:107-113.
34. Zhang S, Ruiz-Echevarria M, Quan Y, Peltz SW: Identification and characterization of a sequence motif involved in nonsense-mediated mRNA decay. Mol Cell Biol 1995, 15:2231-2244.

35. Wilusz CJ, Wang W, Peltz SW: Curbing the nonsense: the activation and regulation of mRNA surveillance. Genes Dev 2001, 15:2781-2785.

36. Mitchell P, Tollervey D: An NMD pathway in yeast involving accelerated deadenylation and exosome-eitd3'- > 5'degradation. Mol Cell 2003, 11:1405-1413.

37. Amrani N, Ganesan R, Kervestin S, Manqus DA, Ghosh S, Jacobson A: A faux3'-UTR promotes aberrant termination and triggers nonsensemediated mRNA decay. Nature 2004, 432:112-118.

38. Leeds P, Peltz SW, Jacobson A, Culbertson MR: The product of the yeast UPF1 gene is required for rapid turnover of mRNAs containing a premature translational termination codon. Genes Dev 1991, 5:2303-2314.

39. Cui Y, Hagan KW, Zhang S, Peltz SW: Identification and characterization of genes that are required for the accelerated degradation of mRNAs containing a premature translational termination codon. Genes Dev 1995, 9:423-436.

40. He F, Jacobson A: Identification of a novel component of the nonsensemediated mRNA decay pathway by use of an interacting protein screen. Genes Dev 1995, 9:437-454

41. Weng Y, Czaplinski K, Peltz SW: Genetic and biochemical characterization of mutations in the ATPase and helicase regions of the Upf1 protein. Mol Cell Biol 1996, 16:5477-5490.

42. Maderazo $A B$, He F, Mangus DA, Jacobson A: Upf1p control of nonsense mRNA translation is regulated by Upf2p and Upf3p. Mol Cell Biol 2000, 20:4591-4603.

43. Keeling KM, Lanier J, Du M, Salas-Marco J, Gao L, Kaenjak-Angeletti A, Bedwell DM: Leaky termination at premature stop codons antagonizes nonsense-mediated mRNA decay in S. cerevisiae. RNA 2004, 10:691-703.

44. Czaplinski K, Weng Y, Hagan KW, Peltz SW: Purification and characterization of the Upf1 protein: a factor involved in translation and mRNA degradation. RNA 1995, 1:610-623.

45. Page MF, Carr B, Anders KR, Grimson A, Anderson P: SMG-2 is a phosphorylated protein required for mRNA surveillance in Caenorhabditis elegans and related to Upf1p of yeast. Mol Cell Biol 1999, 19:5943-5951.

46. Yamashita A, Ohnishi T, Kashima I, Taya Y, Ohno S: Human SMG-1, a novel phosphatidylinositol 3-kinase-related protein kinase, associates with components of the mRNA surveillance complex and is involved in the regulation of nonsense-mediated mRNA decay. Genes Dev 2001, 15:2215-2228.

47. Isken O, Maquat LE: The multiple lives of NMD factors: balancing roles in gene and genome regulation. Nat Rev Genet 2008, 9:699-712.

48. Lelivelt MJ, Culbertson MR: Yeast Upf proteins required for RNA surveillance affect global expression of the yeast transcriptome. Mol Cell Biol 1999, 19:6710-6719.

49. He F, Li X, Spatrick P, Casillo R, Dong S, Jacobson A: Genome-wide analysis of mRNAs regulated by the nonsense-mediated and $5^{\prime}$ to $3^{\prime}$ mRNA decay pathways in yeast. Mol Cell 2003, 12:1439-1452.

50. Guan Q, Zheng W, Tang S, Liu X, Zinkel RA, Tsui KW, Yandell BS, Culbertson MR: Impact of nonsense-mediated mRNA decay on the global expression profile of budding yeast. PLoS Genet 2006, 2:e203.

51. Johansson MJ, Jacobson A: Nonsense-mediated mRNA decay maintains translational fidelity by limiting magnesium uptake. Genes Dev 2010, 24:1491-1495.

52. Welch $E M$, Jacobson $A$ : An internal open reading frame triggers nonsense-mediated decay of the yeast SPT10 mRNA. EMBO J 1999, 18:6134-6145.

53. Gaba A, Jacobson A, Sachs MS: Ribosome occupancy of the yeast CPA1 upstream open reading frame termination codon modulates nonsensemediated mRNA decay. Mol Cell 2005, 20:449-460.

54. Kebaara BW, Atkin AL: Long 3 '-UTRs target wild-type mRNAs for nonsense-mediated mRNA decay in Saccharomyces cerevisiae. Nucleic Acids Res 2009, 37:2771-2778.

55. Belew AT, Advani VM, Dinman JD: Endogenous ribosomal frameshift signals operate as mRNA destabilizing elements through at least two molecular pathways in yeast. Nucleic Acids Res 2011, 39:2799-2808.

56. Lin YY, Qi Y, Lu JY, Pan X, Yuan DS, Zhao Y, Bader JS, Boeke JD: A comprehensive synthetic genetic interaction network governing yeast histone acetylation and deacetylation. Genes Dev 2008, 22:2062-2074. 
57. Costanzo M, Baryshnikova A, Bellay J, Kim Y, Spear ED, Sevier CS, Ding H, Koh JL, Toufighi K, Mostafavi S, Prinz J, St Onge RP, VanderSluis B, Makhnevych T, Vizeacoumar FJ, Alizadeh S, Bahr S, Brost RL, Chen Y, Cokol M, Deshpande R, Li Z, Lin ZY, Liang W, Marback M, Paw J, San Luis BJ, Shuteriqi E, Tong AH, van Dyk N, Wallace IM, Whitney JA, Weirauch MT, Zhong G, Zhu H, Houry WA, Brudno M, Ragibizadeh S, Papp B, Pal C, Roth FP, Giaever G, Nislow C, Troyanskaya OG, Bussey H, Bader GD, Gingras AC, Morris QD, Kim PM, Kaiser CA, Myers CL, Andrews BJ, Boone C: The genetic landscape of a cell. Science 2010, 327:425-431.

58. Gavin AC, Aloy P, Grandi P, Krause R, Boesche M, Marzioch M, Rau C, Jensen $\sqcup$, Bastuck S, Dumpelfeld B, Edelmann A, Heurtier MA, Hoffman V, Hoefert C, Klein K, Hudak M, Michon AM, Schelder M, Schirle M, Remor M, Rudi T, Hooper S, Bauer A, Bouwmeester T, Casari G, Drewes G, Neubauer G, Rick JM, Kuster B, Bork P, Russell RB, Superti-Furga G: Proteome survey reveals modularity of the yeast cell machinery. Nature 2006, 440:631-636.

59. Denning G, Jamieson L, Maquat LE, Thompson EA, Fields AP: Cloning of a novel phosphatidylinositol kinase-related kinase: characterization of the human SMG-1 RNA surveillance protein. J Biol Chem 2001, 276:22709-22714.

60. Gonzalez Cl, Bhattacharya A, Wang W, Peltz SW: Nonsense-mediated mRNA decay in Saccharomyces cerevisiae. Gene 2001, 274:15-25.

61. Penheiter KL, Washburn TM, Porter SE, Hoffman MG, Jaehning JA: A posttranscriptional role for the yeast Paf1-RNA polymerase II complex is revealed by identification of primary targets. Mol Cell 2005, 20:213-223.

62. Wilmes GM, Bergkessel M, Bandyopadhyay S, Shales M, Braberg H, Cagney G, Collins SR, Whitworth GB, Kress TL, Weissman JS, Ideker T, Guthrie C, Krogan NJ: A genetic interaction map of RNA-processing factors reveals links between Sem1/Dss1-containing complexes and mRNA export and splicing. Mol Cell 2008, 32:735-746.

63. Kuperwasser N, Brogna S, Dower K, Rosbash M: Nonsense-mediated decay does not occur within the yeast nucleus. RNA 2004, 10:1907-1915.

64. Segref A, Sharma K, Doye V, Hellwig A, Huber J, Luhrmann R, Hurt E: Mex67p, a novel factor for nuclear mRNA export, binds to both poly(A) + RNA and nuclear pores. EMBO J 1997, 16:3256-3271.

65. Stirling PC, Bloom MS, Solanki-Patil T, Smith S, Sipahimalani P, Li Z, Kofoed M, Ben-Aroya S, Myung K, Hieter P: The complete spectrum of yeast chromosome instability genes identifies candidate CIN cancer genes and functional roles for ASTRA complex components. PLoS Genet 2011, 7:e1002057.

66. Chen W, Struhl K: Saturation mutagenesis of a yeast his3 TATA element: genetic evidence for a specific TATA-binding protein. Proc Natl Acad Sci USA 1988, 85:2691-2695.

67. Gietz RD, Sugino A: New yeast-Escherichia coli shuttle vectors constructed with in vitro mutagenized yeast genes lacking six-base pair restriction sites. Gene 1988, 74:527-534.

68. Cross FR: 'Marker swap' plasmids: convenient tools for budding yeast molecular genetics. Yeast 1997, 13:647-653.

69. Hoke SM, Guzzo J, Andrews B, Brandl CJ: Systematic genetic array analysis links the Saccharomyces cerevisiae SAGA/SLIK and NuA4 component TRA1 to multiple cellular processes. BMC Genet 2008, 9:46.

70. Winzeler EA, Davis RW: Functional analysis of the yeast genome. Curr Opin Genet Dev 1997, 7:771-776.

71. Tong $A H$, Evangelista $M$, Parsons $A B, X u H$, Bader GD, Pagé $N$, Robinson $M$, Raghibizadeh S, Hogue CW, Bussey H, Andrews B, Tyers M, Boone C: Systematic genetic analysis with ordered arrays of yeast deletion mutants. Science 2001, 294:2364-2368.

72. Brandl CJ, Furlanetto AM, Martens JA, Hamilton KS: Characterization of NGG1, a novel yeast gene required for glucose repression of GAL4pregulated transcription. EMBO J 1993, 12:5255-5265.

73. Ausubel FM, Brent R, Kingston RE, Moore DD, Smith JA, Seidman JG, Struhl K: Current Protocols in Molecular Biology New York: John Wiley \& Sons, Inc; 1988.

74. Saccharomyces Genome Database. [http://www.yeastgenome.org/].

75. Langmead B, Trapnell C, Pop M, Salzberg SL: Ultrafast and memoryefficient alignment of short DNA sequences to the human genome. Genome Biol 2009, 10:R25.

76. Li H, Handsaker B, Wysoker A, Fennell T, Ruan J, Homer N, Marth G, Abecasis $G$, Durbin R: 1000 genome project data processing subgroup: the sequence alignment/map format and SAMtools. Bioinformatics 2009, 25:2078-2079. doi:10.1186/1471-2156-13-19

Cite this article as: Kvas et al:: Loss of nonsense mediated decay suppresses mutations in Saccharomyces cerevisiae TRA1. BMC Genetics 2012 13:19

\section{Submit your next manuscript to BioMed Central and take full advantage of:}

- Convenient online submission

- Thorough peer review

- No space constraints or color figure charges

- Immediate publication on acceptance

- Inclusion in PubMed, CAS, Scopus and Google Scholar

- Research which is freely available for redistribution 